\title{
The Application Study of Enterprise Online Reputation Evaluation Index Based on Comprehensive Evaluation of Fuzzy Matter-element
}

\author{
Li Zhou*, Bisong Liu, Zhou Jiang and Cuizhu Meng \\ China national institute of standardization, Beijing, China \\ ${ }^{*}$ Corresponding author
}

\begin{abstract}
Under the background of the development of network economy, enterprise online reputation evaluation and management have become important topics for enterprises. Through research and analysis of enterprise online reputation evaluation models and evaluation indicators, a fuzzy matterelement evaluation model is constructed. The subjective weighting method and objective weighting method are respectively used to calculate the comprehensive weight of enterprise online reputation evaluation indicators and the main elements affecting enterprise online reputation level are obtained through analysis. It provides a scientific reference for enterprises to conduct online reputation evaluation and strengthen online reputation management.
\end{abstract}

Keywords-comprehensive evaluation; fuzzy matter-element; online reputation

\section{INTRODUCTION}

With the development of Internet technology and the promotion of mobile Internet technologies, user experience and sharing of opinions has become the key to online communication. The traditional business model is undergoing transformation, and user evaluation and online reputation have gradually become an important strategic decision-making element [1]. According to Nielsen's research on the degree of trust in advertising consumption, online evaluations account for $68 \%$ of the elements that influence customers consume. Online reputation consists of different opinions of people who have actual experience in social media and on the Internet. User evaluations are based on experience. Some evaluations are relatively objective, while others are not. User evaluations change with many elements. Personal preferences of individuals and evaluations motives will affect the objectivity of evaluation [2]. The impact of online reputation on the relationship between the enterprise and the user is much greater than the brand, so enterprises must make correct evaluation of the situation and pay great attention to the management of online reputation. Launching enterprise online reputation evaluation has become a new topic for enterprises to strengthen online reputation management.

\section{Online Reputation Evaluation Models AND INDICATORS}

Enterprise online reputation evaluation is based on enterprise reputation evaluation with the addition of a wide range of social evaluation. It reflects enterprise online reputation dynamically and objectively in real time through collection of diverse, heterogeneous and multi-party information online. Enterprise online reputation is the possibility that enterprises comply with contracts and fulfill their commitments. It adopts a general 3C evaluation model that considers three basic components of enterprise reputation: Character, reputation and Capacity [3]. The establishment of enterprise online evaluation model shall mainly take into account the willingness, capacity and behavior of enterprises to fulfill their promises in reputation as well as extensive social evaluation, etc. Depending on whether it is decisive for online reputation of the company or reflects the level of online reputation, all evaluation elements are divided into two types: decisive elements and reflective elements. Performance willingness and performance capacity are the decisive elements of enterprise online reputation; performance behavioral expression and social evaluation information are reflective elements of enterprise online reputation [4]. On-line reputation evaluation model is constructed as shown in figure 1 .

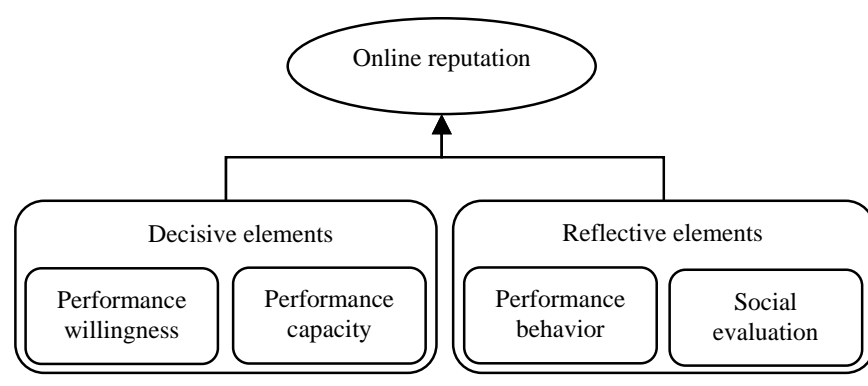

FIGURE I.

ENTERPRISE ONLINE REPUTATION EVALUATION MODEL

According to enterprise online reputation evaluation model and overall consideration of enterprise reputation information items, two types of enterprise online reputation indicators can be initially established: decisive indicators include enterprise basic information (unified social reputation code related information, industry categories, related information, etc.), qualification license information, management information (human resources management, production management, operating management, etc.), transaction information, financial 
information, etc.; reflective indicators include enterprise honor information, social responsibilities, market evaluation (public opinion information), administrative supervision and management, judicial information, etc.

TABLE I. ENTERPRISE ONLINE REPUTATION EVALUATION INDICATORS

\begin{tabular}{|c|c|c|c|}
\hline Objective & Category & Criterion & Indicator \\
\hline \multirow{4}{*}{$\begin{array}{l}\text { Enterprise } \\
\text { online } \\
\text { reputation } \\
\text { evaluation }\end{array}$} & \multirow{2}{*}{$\begin{array}{l}\text { Decisive } \\
\text { indicators }\end{array}$} & $\begin{array}{l}\text { Performance } \\
\text { willingness }\end{array}$ & $\begin{array}{l}\text { Basic information } \\
\text { Qualification } \\
\text { information }\end{array}$ \\
\hline & & $\begin{array}{l}\text { Performance } \\
\text { capacity }\end{array}$ & $\begin{array}{l}\text { Management information } \\
\text { Transaction information } \\
\text { Financial information }\end{array}$ \\
\hline & \multirow[t]{2}{*}{$\begin{array}{l}\text { Reflective } \\
\text { indicators }\end{array}$} & $\begin{array}{l}\text { Performance } \\
\text { behavior }\end{array}$ & \begin{tabular}{lr}
\multicolumn{2}{l}{ Honor information } \\
Social & responsibility \\
information & \\
Administrative & supervision \\
and & management \\
information & \\
\end{tabular} \\
\hline & & $\begin{array}{l}\text { Social } \\
\text { evaluation }\end{array}$ & Public opinion information \\
\hline
\end{tabular}

III. FuZZy MATTER-ELEMENT EVALUATION MODEL CONSTRUCTION

Fuzzy matter-element evaluation method is an organic combination of fuzzy set theory and matter-element analysis theory [5]. Fuzzy sets are used to express the set of fuzzy concepts and described by membership function $\mu_{A}(X) \in[0,1]$. The matter-element analysis method was proposed and established by Professor Cai Wen and focuses on resolving incompatible complex problems. It is an important theoretical basis for extenics and widely used in miacro-decision making of various industries [6]. The values of enterprise online evaluation indicators are fuzzy, so fuzzy matter-element model can be constructed to evaluate enterprise online reputation.

\section{A. Fuzzy Matter-element Model}

For a given matter name $M$, feature $C$ and value $V$, the three elements jointly constitute an ordered ternary $\mathrm{R}=(\mathrm{M}, \mathrm{C}, \mathrm{V})$ as the basic element of evaluation (referred to as matterelement). C refers to the corresponding evaluation object indicator and $\mathrm{V}$ refers to its indicator value. If $\mathrm{V}$ is fuzzy, it will become a fuzzy matter-element. If the matter $M$ has $n$ features of $C_{1}, C_{2}, \ldots, C_{n}$ and corresponding values of $V_{1}, V_{2}, \ldots, V_{n}$ for description, then $\mathrm{M}$ is called n-dimensional fuzzy matter element. For n-dimensional compound matter-element $R_{m n}$ of $\mathrm{m}$ matters, the corresponding matrix is expressed as follows:

$$
R_{m n}=\left[\begin{array}{ccccc} 
& M_{1} & M_{2} & \cdots & M_{m} \\
C_{1} & X_{11} & X_{21} & \cdots & X_{m 1} \\
C_{2} & X_{12} & X_{22} & \cdots & X_{m 2} \\
\vdots & \vdots & \vdots & & \vdots \\
C_{n} & X_{1 n} & X_{2 n} & \cdots & X_{m n}
\end{array}\right]
$$

\section{B. Preference Membership Fuzzy Matter-element Model}

The evaluation process of matter involves many evaluation indicators. If there are no uniform metrics among the indicators, the evaluation process will be difficult to perform. Corresponding fuzzy value membership degree of corresponding fuzzy value of each individual evaluation indicator is called the preference membership. The principle established thereout is called the principle of preference membership [7]. In order to transform the fuzzy matter-element matrix into a preference membership matrix, the preference principle is introduced. Generally there are two types of indicators:

$$
\begin{aligned}
& \max X_{j}=\max \left(X_{1 j}, X_{2 j}, \cdots, X_{m j}\right) \\
& \min X_{j}=\min \left(X_{1 j}, X_{2 j}, \cdots, X_{m j}\right)
\end{aligned}
$$

The-smaller-the-better type:

$$
\mu_{i j}=\frac{X_{i j}}{\min X_{j}}
$$

The-bigger-the-better type:

$$
\mu_{i j}=\frac{X_{i j}}{\max X_{j}}
$$

Where $\mu_{i j}$ refers to the dimensionless result of the corresponding value of No. i matter and No. $\mathrm{j}$ feature; $\max X_{j}$ refers to the maximum corresponding value of the No. j feature of the matter evaluated; $\min X_{j}$ refers to the minimum corresponding value of the No. $j$ feature of the matter evaluated. Formula (6) is obtained after processing of values in formula (1) through formula (4) and formula (5), that is, preference membership fuzzy matter-element $\tilde{R}_{m n}$.

$$
\tilde{R}_{m n}=\left[\begin{array}{ccccc} 
& M_{1} & M_{2} & \cdots & M_{m} \\
C_{1} & \mu_{11} & \mu_{21} & \cdots & \mu_{m 1} \\
C_{2} & \mu_{12} & \mu_{22} & \cdots & \mu_{m 2} \\
\vdots & \vdots & \vdots & & \vdots \\
C_{n} & \mu_{1 n} & \mu_{2 n} & \cdots & \mu_{m n}
\end{array}\right]
$$




\section{Establish Difference Square Compound Fuzzy Matter- element Matrix}

Generally speaking, the standard fuzzy matter-element $R_{0 n}$ is determined by the maximum or minimum value among the preference membership fuzzy matter-element $\tilde{R}_{m n}$; perform difference calculation of standard fuzzy matter-element $R_{0 n}$ and preference membership fuzzy matter-element $\tilde{R}_{m n}$ to get the $\Delta_{i j}$ that is the square of difference between standard fuzzy matter-element and preference membership fuzzy matterelement. Different $\Delta_{i j}$ form difference square compound fuzzy matter-element.

$$
R_{\Delta}=\left[\begin{array}{ccccc} 
& M_{1} & M_{2} & \cdots & M_{m} \\
C_{1} & \Delta_{11} & \Delta_{21} & \cdots & \Delta_{m 1} \\
C_{2} & \Delta_{12} & \Delta_{22} & \cdots & \Delta_{m 2} \\
\vdots & \vdots & \vdots & & \vdots \\
C_{n} & \Delta_{1 n} & \Delta_{2 n} & \cdots & \Delta_{m n}
\end{array}\right]
$$

\section{Determine the Weight}

In the comprehensive evaluation, the weight of evaluation indicator directly affects the accuracy of evaluation results. Common subjective weighting methods include Delphi Method and AHP method; objective weighting methods include principal component analysis method, maximum deviation method, entropy method, etc [8]. AHP method and entropy weight method are respectively adopted below and applied in fuzzy matter-element model for evaluation. AHP method is first adopted below to calculate the subjective weight; entropy weight method is adopted to determine the objective weight. Finally, AHP method and entropy weight method are organically combined to get comprehensive weight.

\section{1) AHP method}

Analytic hierarchy process is called AHP for short. First proposed by Satty, an operational research expert in the United States, it is a decision analysis method that quantifies qualitative problems based on hierarchy [9]. The method is establish the evaluation system of hierarchical structure; secondly, 9-scale method is used to construct the comparison matrix of indicator layers; then, the judgment matrix passes the consistency test to obtain the subjective weight of indicators $\alpha_{j}$.

\section{2) Entropy method}

Entropy method is a method used to determine the weight of indicators that is made up of evaluation indicators. In enterprise reputation evaluation, the weight is determined by calculation of entropy, which is a method to objectively determine each evaluation indicator, and the evaluation result is more truthful [10]. For a certain indicator, the greater the difference in indicator value ${ }_{j i}$, the greater the role that the indicator plays in comprehensive evaluation is and the greater the corresponding weight value is. For $\mathrm{m}$ evaluation matters, evaluation indicator matrix of $\mathrm{n}$ evaluation indicators $X=\left(x_{j i}\right)_{m \times n}$; normalization processing is performed to form a normalized judgment matrix.

The entropy of No. $\mathrm{j}$ evaluation indicator is calculated as follows:

$$
\begin{aligned}
& H_{j}=-\frac{1}{\ln m}\left(\sum_{i=1}^{m} f_{j i} \ln f_{j i}\right) \\
& (i=1,2, \cdots, m ; j=1,2, \cdots, n)
\end{aligned}
$$

$$
f_{j i}=\frac{1+\mu_{j i}}{\sum_{i=1}^{m}\left(1+\mu_{j i}\right)}
$$

Calculate the index of entropy weight W:

$$
W=\left(\omega_{j}\right)_{1 \times n}
$$

Wherein,

$$
\omega_{j}=\frac{1-H_{j}}{n-\sum_{j=1}^{n} H_{j}} \sum_{\text {and }}^{n} \omega_{j}=1
$$

\section{3) Comprehensive weight}

The following formula is used to determine comprehensive weight:

$$
\beta_{j}=\frac{\alpha_{j} \omega_{j}}{\sum_{j=1}^{n}\left(\alpha_{j} \omega_{j}\right)}
$$

\section{E. Evaluation Results}

The evaluation results of each enterprise are calculated according to the value of each indicator and the comprehensive weight calculated above. After comparative analysis, enterprises with higher evaluation results are obtained. The main practices of enterprises on management of online reputation can be known by analyzing the indicator values of enterprises with higher evaluation results. 


\section{APPLICATION ANALYSES}

Four dimensions of enterprise online reputation evaluation are taken into account comprehensively; 8 comprehensive evaluation indicators are selected as basic evaluation indicators, including quality license information $\mathrm{C}_{1}$, management information $\mathrm{C}_{2}$, transaction information $\mathrm{C}_{3}$, financial information $\mathrm{C}_{4}$, administrative supervision and management $\mathrm{C}_{5}$, social responsibility information $\mathrm{C}_{6}$, honor information $\mathrm{C}_{7}$ and public opinion information $\mathrm{C}_{8}$.

TABLE II. PROCESSING VALUES OF COMPREHENSIVE EVALUATION INDICATORS

\begin{tabular}{|c|c|c|c|c|c|c|}
\hline $\mathbf{X}_{\mathbf{i j}}$ & $\mathbf{Q}_{\mathbf{1}}$ & $\mathbf{Q}_{\mathbf{2}}$ & $\mathbf{Q}_{\mathbf{3}}$ & $\mathbf{Q}_{\mathbf{4}}$ & $\mathbf{Q}_{\mathbf{5}}$ & $\mathbf{Q}_{\mathbf{6}}$ \\
\hline $\mathbf{C}_{\mathbf{1}}$ & 20.0 & 21.1 & 21.7 & 20.4 & 21.2 & 22.0 \\
\hline $\mathbf{C}_{\mathbf{2}}$ & 49.5 & 57.2 & 58.0 & 56.2 & 61.3 & 62.4 \\
\hline $\mathbf{C}_{\mathbf{3}}$ & 16.6 & 20.3 & 19.2 & 17.0 & 22.1 & 20.8 \\
\hline $\mathbf{C}_{\mathbf{4}}$ & 50.15 & 58.2 & 57.16 & 50.64 & 61.32 & 58.95 \\
\hline $\mathbf{C}_{\mathbf{5}}$ & 26.35 & 26.5 & 26.14 & 25.68 & 28.22 & 29.92 \\
\hline $\mathbf{C}_{\mathbf{6}}$ & 68.8 & 72.8 & 70.0 & 63.5 & 77.0 & 74.5 \\
\hline $\mathbf{C}_{\mathbf{7}}$ & 76.48 & 53.95 & 38.91 & 141.07 & 85.59 & 55.2 \\
\hline $\mathbf{C}_{\mathbf{8}}$ & 2.28 & 2.23 & 1.89 & 2.29 & 2.44 & 2.19 \\
\hline
\end{tabular}

The membership fuzzy matter-element matrix is constructed according to formula (4) and (5):

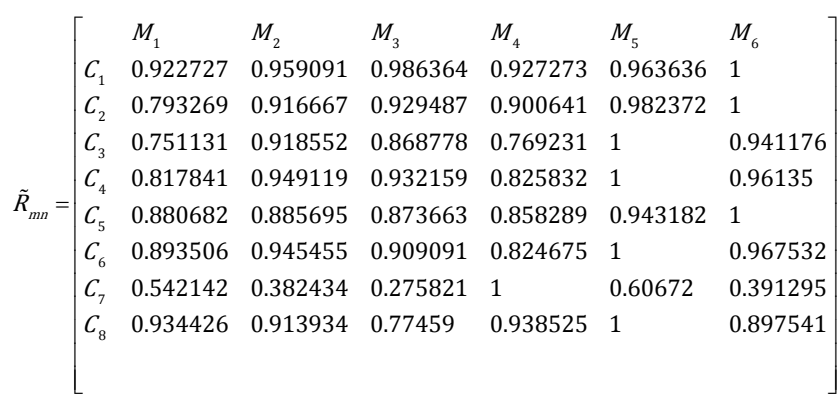

The difference square compound fuzzy matter element matrix is established according to that the standard fuzzy matter-element is determined by the maximum value of preference membership fuzzy membership matter-element:

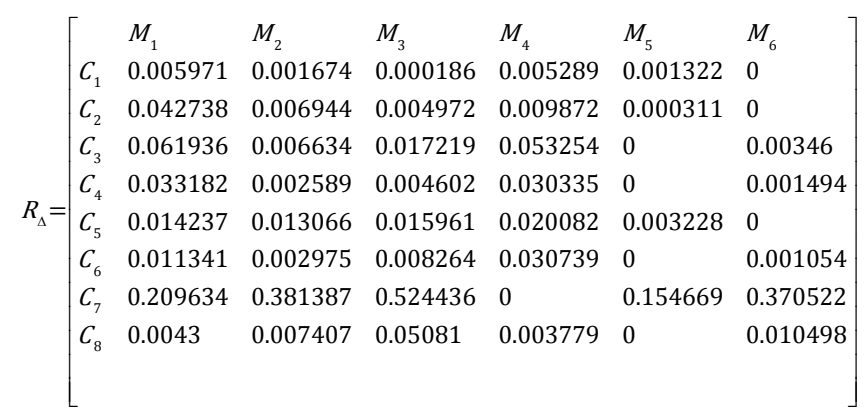

\section{A. Determine the Weight by AHP Method}

The information values and weights calculated according to the AHP calculation procedures are as shown in table 3. It can be seen from the table that $C_{7}$ honor information among the comprehensive evaluation indicators has the greatest influence on the enterprise online reputation evaluation and has the largest weight of up to 0.3969 ; it is followed by public opinion information with a weight of 0.1982 . The other information has a relative small impact on enterprise online reputation and the weight is also low.

TABLE III. INFORMATION VALUE AND WEIGHT OF EACH COMPREHENSIVE EVALUATION INDICATOR

\begin{tabular}{|c|c|c|c|c|c|c|c|c|}
\hline $\begin{array}{c}\text { Indi } \\
\text { cato } \\
\mathbf{r}\end{array}$ & $\mathbf{C}_{\mathbf{1}}$ & $\mathbf{C}_{\mathbf{2}}$ & $\mathbf{C}_{\mathbf{3}}$ & $\mathbf{C}_{\mathbf{4}}$ & $\mathbf{C}_{\mathbf{5}}$ & $\mathbf{C}_{\mathbf{6}}$ & $\mathbf{C}_{\mathbf{7}}$ & $\mathbf{C}_{\mathbf{8}}$ \\
\hline $\begin{array}{c}\text { Info } \\
\text { rmat } \\
\text { ion } \\
\begin{array}{c}\text { Valu } \\
\text { e }\end{array}\end{array}$ & $\begin{array}{c}0.14 \\
65\end{array}$ & $\begin{array}{c}0.13 \\
06\end{array}$ & $\begin{array}{c}0.27 \\
98\end{array}$ & $\begin{array}{c}0.18 \\
54\end{array}$ & $\begin{array}{c}0.16 \\
26\end{array}$ & $\begin{array}{c}0.14 \\
29\end{array}$ & $\begin{array}{c}1.02 \\
74\end{array}$ & $\begin{array}{c}0.51 \\
30\end{array}$ \\
\hline $\begin{array}{c}\text { Wei } \\
\text { ght }\end{array}$ & $\begin{array}{c}0.05 \\
66\end{array}$ & $\begin{array}{c}0.05 \\
05\end{array}$ & $\begin{array}{c}0.10 \\
81\end{array}$ & $\begin{array}{c}0.07 \\
16\end{array}$ & $\begin{array}{c}0.06 \\
28\end{array}$ & $\begin{array}{c}0.05 \\
52\end{array}$ & $\begin{array}{c}0.39 \\
69\end{array}$ & $\begin{array}{c}0.19 \\
82\end{array}$ \\
\hline
\end{tabular}

\section{B. Determine Weight through Entropy Weight Method}

Normalization processing is performed to calculate the entropy $\mathrm{H}_{\mathrm{j}}$ and weight $\mathrm{W}$ of each indicator as shown in table 4 . It can be seen from the table that $\mathrm{C} 4$ transaction information among the comprehensive evaluation indicators has the greatest influence on the enterprise online reputation evaluation and has the largest weight of up to 0.1270 ; it is followed by administrative supervision and management information with a weight of 0.1269 . The other information has a relative small impact on enterprise online reputation and the weight is also low.

TABLE IV. ENTROPY AND WEIGHT OF EACH COMPREHENSIVE EVALUATION INDICATOR

\begin{tabular}{|c|c|c|c|c|c|c|c|c|}
\hline $\begin{array}{c}\text { Indic } \\
\text { ator }\end{array}$ & $\mathbf{C}_{\mathbf{1}}$ & $\mathbf{C}_{\mathbf{2}}$ & $\mathbf{C}_{\mathbf{3}}$ & $\mathbf{C}_{\mathbf{4}}$ & $\mathbf{C}_{\mathbf{5}}$ & $\mathbf{C}_{\mathbf{6}}$ & $\mathbf{C}_{\mathbf{7}}$ & $\mathbf{C}_{\mathbf{8}}$ \\
\hline $\begin{array}{c}\text { Entr } \\
\text { opy }\end{array}$ & $\begin{array}{c}0.846 \\
9\end{array}$ & $\begin{array}{c}0.851 \\
3\end{array}$ & $\begin{array}{c}0.847 \\
1\end{array}$ & $\begin{array}{c}0.846 \\
3\end{array}$ & $\begin{array}{c}0.846 \\
5\end{array}$ & $\begin{array}{c}0.851 \\
0\end{array}$ & $\begin{array}{c}0.848 \\
6\end{array}$ & $\begin{array}{c}0.852 \\
3\end{array}$ \\
\hline $\begin{array}{c}\text { Weig } \\
\text { ht }\end{array}$ & $\begin{array}{c}0.126 \\
5\end{array}$ & $\begin{array}{c}0.122 \\
9\end{array}$ & $\begin{array}{c}0.126 \\
4\end{array}$ & $\begin{array}{c}0.127 \\
0\end{array}$ & $\begin{array}{c}0.126 \\
9\end{array}$ & $\begin{array}{c}0.123 \\
2\end{array}$ & $\begin{array}{c}0.125 \\
1\end{array}$ & $\begin{array}{c}0.122 \\
0\end{array}$ \\
\hline
\end{tabular}

\section{Calculate Comprehensive Weight}

Comprehensive weight is calculated according to formula (10) as shown in table 5 . It can be seen from the table that honor information, public opinion information and transaction information have a greater impact on enterprise online evaluation after the comprehensive calculation, followed by financial information, administrative supervision and management information, qualification license information, social responsibility information and management information. This result is also in line with the general judgment that enterprise performance behavior and social evaluation information as reflective information have a greater impact on the level of enterprise online reputation. 
TABLE V. COMPREHENSIVE WEIGHT OF EACH COMPREHENSIVE INDICATOR

\begin{tabular}{|c|c|c|c|c|c|c|c|c|}
\hline $\begin{array}{c}\text { Indi } \\
\text { cato } \\
\text { r }\end{array}$ & $\mathrm{C}_{1}$ & $\mathrm{C}_{2}$ & $\mathrm{C}_{3}$ & $\mathrm{C}_{4}$ & $\mathrm{C}_{5}$ & $\mathrm{C}_{6}$ & $\mathrm{C}_{7}$ & $\mathrm{C}_{8}$ \\
\hline $\begin{array}{l}\text { AHP } \\
\text { Met } \\
\text { hod }\end{array}$ & $\begin{array}{c}0.056 \\
6\end{array}$ & $\begin{array}{c}0.050 \\
5\end{array}$ & $\begin{array}{c}0.108 \\
1\end{array}$ & $\begin{array}{c}0.071 \\
6\end{array}$ & $\begin{array}{c}0.062 \\
8\end{array}$ & $\begin{array}{c}0.055 \\
2\end{array}$ & $\begin{array}{c}0.396 \\
9\end{array}$ & $\begin{array}{c}0.198 \\
2\end{array}$ \\
\hline $\begin{array}{l}\text { Entr } \\
\text { opy } \\
\text { Met } \\
\text { hod } \\
\end{array}$ & $\begin{array}{c}0.126 \\
5\end{array}$ & $\begin{array}{c}0.122 \\
9\end{array}$ & $\begin{array}{c}0.126 \\
4\end{array}$ & $\begin{array}{c}0.127 \\
0\end{array}$ & $\begin{array}{c}0.126 \\
9\end{array}$ & $\begin{array}{c}0.123 \\
2\end{array}$ & $\begin{array}{c}0.125 \\
1\end{array}$ & $\begin{array}{c}0.122 \\
0\end{array}$ \\
\hline $\begin{array}{c}\text { Com } \\
\text { preh } \\
\text { ensiv } \\
\text { e } \\
\text { meth } \\
\text { od }\end{array}$ & $\begin{array}{c}0.057 \\
4\end{array}$ & $\begin{array}{c}0.049 \\
8\end{array}$ & $\begin{array}{c}0.109 \\
6\end{array}$ & $\begin{array}{c}0.072 \\
9\end{array}$ & $\begin{array}{c}0.063 \\
9\end{array}$ & $\begin{array}{c}0.054 \\
5\end{array}$ & $\begin{array}{c}0.398 \\
1\end{array}$ & $\begin{array}{c}0.193 \\
9\end{array}$ \\
\hline
\end{tabular}

\section{Calculation Results}

It can be concluded that the level of enterprise online reputation is as shown in table 6 by measuring calculating the online reputation evaluation results of each company. Among then, company $\mathrm{Q}_{4}$ has highest level of online reputation, followed by $\mathrm{Q}_{5}, \mathrm{Q}_{1}, \mathrm{Q}_{6}, \mathrm{Q}_{2}$ and $\mathrm{Q}_{3}$; it can be seen from analysis of enterprises with a high level of online reputation that enterprises have high scores in terms of honor information, public opinion information, social responsibility information, transaction information and other reflective indicators. The external performance information is also the main element that affects enterprise online reputation. Therefore, enterprises must strengthen online reputation management and shall pay more attention to the reflective indicators of company in addition to strengthening internal management.

TABLE VI. ONLINE REPUTATION EVALUATION OF EACH ENTERPRISE

\begin{tabular}{|c|c|c|c|c|c|c|}
\hline $\begin{array}{c}\text { Enterpri } \\
\text { se }\end{array}$ & $\mathbf{Q}_{\mathbf{1}}$ & $\mathbf{Q}_{\mathbf{2}}$ & $\mathbf{Q}_{\mathbf{3}}$ & $\mathbf{Q}_{\mathbf{4}}$ & $\mathbf{Q}_{\mathbf{5}}$ & $\mathbf{Q}_{\mathbf{6}}$ \\
\hline $\begin{array}{c}\text { Weighte } \\
\text { d Value }\end{array}$ & 49.4043 & 41.9874 & 35.0432 & 75.2232 & 55.9634 & 43.1385 \\
\hline
\end{tabular}

\section{CONCLUSION}

The level of enterprise online reputation has a more and more far-reaching impact on the survival and development of enterprises in the current network economic environment and even surpasses the impact of brand to a certain extent. Therefore, mastering the main elements that affect enterprise online reputation and thus achieving scientific online reputation management appear to be particularly important. This paper constructs a fuzzy matter-element model by studying and analyzing enterprise online reputation model and evaluation indicator through research and analysis of enterprise online reputation evaluation model and evaluation indicator. The subjective weighting method and objective weighting method are respectively used to calculate to get that the main elements affecting enterprise online reputation level are enterprise honor information, public opinion information, transaction information and other reflective indicators. It provides a scientific reference for enterprises to improve online reputation management level.

\section{ACKNOWLEDGMENT}

Li Zhou, Bisong Liu, Zhou Jiang and Cuizhu Meng thank National Key R\&D Program of China.

\section{REFERENCES}

[1] ZHANG Wei, LIU Lu, ZHU Yan-chun, Recent Developments and Prospect of Online Reputation Systems[J], Control and Decision, 2005(11),pp3-9,13.

[2] YU Zhao-ji, Lü Liang-sheng, HU Xiang-pei, Research on the Influencing Factors of Online Reputation Evaluation and Countermeasures Under the Behavior System[J], Journal of Northeastern University(Social Science) , 2011(06),pp506-510.

[3] GB/T 31863-2015, Evaluation index of enterprise quality credit.

[4] Zhou Li. 2014. Understanding of 'Implement specifications for enterprise quality trustworthiness management'[J], China quality supervision, 04,pp 18-21.

[5] HUANG Yongcai, XU Mengguo, WANG Ping;LIU Chang, ZHANG Qiang, DU Yuxiang, Scraper Optimization Based on Variation Coefficient Method and Fuzzy Matter Element Model[J], Mining Research and Development , 2016(07), pp 100-104.

[6] WANG Mei, TANG De-shan, MENG Zhen-zhu, BAI Yi-fan, Application of Comprehensive Evaluation Model Based Fuzzy Matterelement in Evaluation of Regional Human-Water Harmony[J], Water Resources and Power , 2015(02),pp 160-163,134.

[7] FU Lijia, XIE Shiping, FAN Zhaoli, Application of Fuzzy Matterelement Model in Evaluation for Operating Safety of Highway Tunnels[J], Technology of Highway and Transport , 2015(02),pp 122126.

[8] NIU Jun-feng, SUN Jing-juan, LI Sheng-hou,ZHANG Xiu-jun, Airport Operation Safety Assessment Based on Fuzzy Matter Element Model with Comprehensive Weighting[J], Fire Control \& Command Control, 2017(04),pp101-104,109.

[9] WANG Li-juan, ZHANG Tian-jun, WANG Rong;JIA Zheng-ping, ZHANG Juan-hong, Application of Optimal Fuzzy Matter Element Model Based on AHP Method in Evaluation of Quality of Angelica Sinensis Seeds[J], Medical \& Pharmaceutical Journal of Chinese People’s Liberation Army , 2016(07),pp 105-109.

[10] LIU Caihong, XU Fuyuan, Fuzzy Matter Element Based Evaluation of QualityRisk in ManufacturingSupplyChain[J], Journal of University of Shanghai for Science and Technology , 2016(05),pp 465-471. 